\title{
The sensitivity to change of the cluster headache quality of life scale assessed before and after deep brain stimulation of the ventral tegmental area
}

Davide Cappon 1,2,3, Agata Ryterska 1,4, Harith Akram', Susie Lagrata ${ }^{5}$, Sanjay Cheema4, Jonathan Hyam', Ludvic Zrinzo ${ }^{1}$, Manjit Matharu ${ }^{4}$ and Marjan Jahanshahi ${ }^{1,6^{*}}$

\begin{abstract}
Background: Cluster headache $(\mathrm{CH})$ is a trigeminal autonomic cephalalgia (TAC) characterized by a highly disabling headache that negatively impacts quality of life and causes limitations in daily functioning as well as social functioning and family life. Since specific measures to assess the quality of life (QoL) in TACs are lacking, we recently developed and validated the cluster headache quality of life scale $(\mathrm{CH}-\mathrm{QoL})$. The sensitivity of $\mathrm{CH}-\mathrm{QoL}$ to change after a medical intervention has not been evaluated yet.

Methods: This study aimed to test the sensitivity to change of the $\mathrm{CH}-\mathrm{QoL}$ in $\mathrm{CH}$. Specifically we aimed to (i) assess the sensitivity of $\mathrm{CH}$-QoL to change before and following deep brain stimulation of the ventral tegmental area (VTA-DBS), (ii) evaluate the relationship of changes on $\mathrm{CH}-\mathrm{QoL}$ with changes in other generic measures of quality of life, as well as indices of mood and pain. Ten consecutive $\mathrm{CH}$ patients completed the $\mathrm{CH}$-QoL and underwent neuropsychological assessment before and after VTA-DBS. The patients were evaluated on headache frequency, severity, and load (HAL) as well as on tests of generic quality of life (Short Form-36 (SF-36)), mood (Beck Depression Inventory, Hospital Anxiety and Depression Rating Scale), and pain (McGill Pain Questionnaire, Headache Impact Test, Pain Behaviour Checklist).

Results: The CH-QoL total score was significantly reduced after compared to before VTA-DBS. Changes in the CHQoL total score correlated significantly and negatively with changes in HAL, the SF-36, and positively and significantly with depression and the evaluative domain on the McGill Pain Questionnaire.

(Continued on next page)
\end{abstract}

\footnotetext{
* Correspondence: m.jahanshahi@ucl.ac.uk

1 Unit of Functional Neurosurgery, Department of Clinical and Movement

Neurosciences, University College London (UCL) Institute of Neurology,

National Hospital for Neurology and Neurosurgery, 33 Queen Square, WC1N

3BG London, UK

${ }^{6}$ MOE Key Lab for Neuroinformation, The Clinical Hospital of Chengdu Brain

Science Institute, University of Electronic Science and Technology of China, Chengdu, China

Full list of author information is available at the end of the article
}

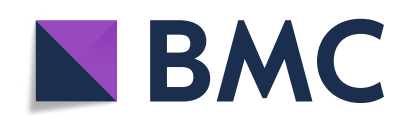

(- The Author(s). 2021 Open Access This article is licensed under a Creative Commons Attribution 4.0 International License, which permits use, sharing, adaptation, distribution and reproduction in any medium or format, as long as you give appropriate credit to the original author(s) and the source, provide a link to the Creative Commons licence, and indicate if changes were made. The images or other third party material in this article are included in the article's Creative Commons licence, unless indicated otherwise in a credit line to the material. If material is not included in the article's Creative Commons licence and your intended use is not permitted by statutory regulation or exceeds the permitted use, you will need to obtain permission directly from the copyright holder. To view a copy of this licence, visit http://creativecommons.org/licenses/by/4.0/. The Creative Commons Public Domain Dedication waiver (http://creativecommons.org/publicdomain/zero/1.0/) applies to the data made available in this article, unless otherwise stated in a credit line to the data. 


\begin{abstract}
(Continued from previous page)
Conclusions: Our findings demonstrate that changes after VTA-DBS in CH-QoL total scores are associated with the reduction of frequency, duration, and severity of headache attacks after surgery. Moreover, post VTA-DBS

improvement in $\mathrm{CH}-\mathrm{Q} o \mathrm{~L}$ scores is associated with an amelioration in quality of life assessed with generic measures, a reduction of depressive symptoms, and evaluative pain experience after VTA-DBS. These results support the sensitivity to change of the $\mathrm{CH}-\mathrm{QoL}$ and further demonstrate the validity and applicability of $\mathrm{CH}-\mathrm{QoL}$ as a disease specific measure of quality of life for $\mathrm{CH}$.
\end{abstract}

Keywords: Cluster headache, Trigeminal autonomic cephalalgias, Quality of life scale, Deep brain stimulation

\section{Introduction}

Quality of life (QoL) scales have increasingly emerged as an essential clinical outcome measure for assessing the impact of a disorder, the symptoms, and its medical or surgical treatment on patients' well-being and daily life. Trigeminal autonomic cephalalgias (TACs) are a group of primary headaches including cluster headache $(\mathrm{CH})$, paroxysmal hemicrania, hemicrania continua, and shortlasting unilateral neuralgiform headache attacks [1]. $\mathrm{CH}$ is the most common form of TAC and is characterized by a highly disabling headache that is strictly unilateral (with occasional side switching). $\mathrm{CH}$ causes excruciating pain associated with prominent cranial autonomic features and a sense of restlessness or agitation. Quality of life studies in patients with $\mathrm{CH}$ have shown limitations in normal daily functioning as well as in social functioning and family life $[2,3]$.

Specific measures to assess QoL are lacking and assessment of quality of life in this population is currently limited to the use of a combination of tests including generic quality of life scales such as the SF-36 [4]. However, these measures might not be specifically sensitive for $\mathrm{CH}$ and might, for example, fail to discriminate between $\mathrm{CH}$ patients and migraineurs, highlighting the need for a specific scale to assess QoL in CH [5].

In light of this, we previously developed and validated (on a total of 406 patients) the first patient-reported outcome measure to specifically monitor QoL in patients with $\mathrm{CH}$ in clinical care and research [6]. It was shown that the cluster headache quality of life scale (CH-QoL) has essential psychometric properties, including good construct validity, convergent validity, internal consistency and test retest reliability [6]. An important aspect of the validity of a clinical scale is its sensitivity to change, most importantly reflecting change after a medical or surgical intervention [7].

In a significant number of highly disabled individuals, standard medical therapy is not sufficiently effective to treat headache attacks in $\mathrm{CH}$. For these patients, ventral tegmental area deep brain stimulation (VTA-DBS) has been demonstrated to reduce the frequency, severity and duration of headache attacks, and to lower anxiety levels and pain seeking behavior associated with the attacks $[8$,
9]. DBS is a surgical treatment in which electric pulses are continuously applied via stereotactically implanted electrodes and is now considered as a therapeutic option for refractory $\mathrm{CH}$ with proven efficacy [10].

The aim of the present study was to evaluate the sensitivity to change of the CH-QoL. Specifically, the aims were (i) to assess the sensitivity of CH-QoL to change before and after VTA-DBS intervention, (ii) to assess the association of change on $\mathrm{CH}-\mathrm{QoL}$ with change in other generic standardized measures of quality of life, as well as indices of mood and pain in $\mathrm{CH}$.

\section{Methods \\ Study population}

Ten consecutive patients with cluster headache undergoing VTA-DBS at the National Hospital for Neurology and Neurosurgery in London UK were enrolled (Table 1). All enrolled participants underwent clinical examination, neuropsychological assessment and completed the $\mathrm{CH}$ QoL prior to surgery and one year or longer postoperatively. The surgical procedure has been described previously [8] and involved DBS lead (model 3389, Medtronic Inc.) implantation in the ipsilateral VTA or bilaterally (if symptoms were side alternating) under local or general anesthesia.

\section{Assessment of headache frequency, severity and load}

Data on headache frequency, duration and severity were obtained from a "headache diary" completed by patients at the relevant time points. Headache severity was evaluated on a verbal rating scale (VRS) for pain (0, no pain, to 10 , the worst pain imaginable). Headache frequency was described as the number of $\mathrm{CH}$ episodes per day. Headache load (HAL) is a composite score to simultaneously measure frequency, severity and duration of cluster headache episodes. It was calculated as $\Sigma$ (severity [verbal rating scale] $x$ duration [in hours]) of all headache attacks experienced over a 2-week period [8].

\section{Cluster headache quality of life scale (CH-QoL)}

$\mathrm{CH}$-QoL scale consists of 28 items that are answered on a four points scale $($ Never $=0$ to Always $=4$ ). In addition to a total score, 4 sub-scores factors can be derived: 
Table 1 Demographic and headache characteristics. $M=$ male, $F=$ female, $H A L=$ headache load, DBS = deep brain stimulation, $M=$ mean, $\mathrm{SD}=$ standard deviation. Age, education and duration units are years.

\begin{tabular}{|c|c|c|c|c|c|c|c|c|c|c|c|}
\hline ID & Gender & Age & Education & Duration & $\begin{array}{l}\text { Side of } \\
\text { attacks }\end{array}$ & $\begin{array}{l}\text { Headache } \\
\text { frequency pre- } \\
\text { DBS }\end{array}$ & $\begin{array}{l}\text { Headache } \\
\text { frequency post- } \\
\text { DBS }\end{array}$ & $\begin{array}{l}\text { Headache } \\
\text { severity pre- } \\
\text { DBS }\end{array}$ & $\begin{array}{l}\text { Headache } \\
\text { severity post- } \\
\text { DBS }\end{array}$ & $\begin{array}{l}\text { HAL } \\
\text { pre- } \\
\text { DBS }\end{array}$ & $\begin{array}{l}\text { HAL } \\
\text { post- } \\
\text { DBS }\end{array}$ \\
\hline 1 & $M$ & 46 & 11 & 7 & Right & 3-4/day & 3/day & $6-8 / 10$ & $5-6 / 10$ & 275 & 156 \\
\hline 2 & $\mathrm{~F}$ & 41 & 19 & 4 & Bilateral & 3-5/day & 1/day & $6-9 / 10$ & $5-6 / 10$ & 1964 & 347 \\
\hline 3 & M & 58 & 10 & 14 & Left & 2/day & 1-2/day & $6-8 / 10$ & $7-9 / 10$ & 840 & 520 \\
\hline 4 & $\mathrm{~F}$ & 42 & 17 & 21 & Bilateral & 2-4/day & 2-7/day & $9-10 / 10$ & $9-10 / 10$ & 2178 & 2543 \\
\hline 5 & M & 43 & 10 & 28 & Right & 5-15/day & 8/day & $7-8 / 10$ & $9-10 / 10$ & 865 & 994 \\
\hline 6 & M & 37 & 11 & 23 & Right & 5/day & 4-5/week & $9-10 / 10$ & $8-9 / 10$ & 764 & 78 \\
\hline 7 & M & 39 & 11 & 13 & Bilateral & 3-6/day & $12 /$ month & $5-9 / 10$ & $5-7 / 10$ & 700 & 20 \\
\hline 8 & M & 41 & 16 & 15 & Left & 7-10/day & 2-3/day & $8-10 / 10$ & $6-7 / 10$ & 1387 & 75 \\
\hline 9 & M & 59 & 11 & 20 & Left & 5-7/day & 6-7/day & $7-9 / 10$ & $7-8 / 10$ & 519 & 603 \\
\hline \multirow[t]{2}{*}{10} & M & 48 & 11 & 15 & Right & 3/day & 1-2/day & $2-6 / 10$ & $2-6 / 10$ & 379 & 198 \\
\hline & $80 \% \mathrm{M}$ & $\begin{array}{l}\text { M 45.4 } \\
\text { SD (11.9) }\end{array}$ & $\begin{array}{l}12.7 \\
(2.9)\end{array}$ & $\begin{array}{l}16.0 \\
(7.1)\end{array}$ & & & & & & $\begin{array}{l}1964 \\
(649)\end{array}$ & $\begin{array}{l}347 \\
(762)\end{array}$ \\
\hline
\end{tabular}

F1 Restrictions of activities of daily living items 1-9; F2 Impact on mood and interpersonal relationships items 10-21; F3 Pain and anxiety items 22-23; F4 Lack of vitality items $24-28$. The total scores range from 0 to 112 with higher scores indicating poorer health related quality of life [6] (seeTable 2).

\section{Assessment of generic quality of life, mood and pain Generic quality of life scale -SF-36}

The Short Form-36 (SF-36) [11] is a 36-item questionnaire which measures generic Quality of Life (QoL) across eight domains (physical and social functioning, physical and emotional role limitations, mental health, energy, pain, and general health perceptions). Eight different sub-scores, and a physical and mental summary score, can be derived. The maximum score ranges from 0 (lowest or worst possible level of functioning) to 100 (indicates the best possible health state).

\section{Mood}

The Beck Depression Inventory (BDI-II) [12] is a selfreport measure of the severity of depression with regard to cognitive, affective, somatic, or behavioral symptoms. Scores range from 0 to 63 , with higher scores denoting higher depression.

The Hospital Anxiety and Depression Rating Scale (HADS) [13] is a self-report measure assessing depression and anxiety. The sum of items in each subscale

Table 2 Cluster headache quality of life scale (CH-QoL) total and subscale scores before (pre-op) and after ventral tegmental area deep brain stimulation (VTA-DBS)

\begin{tabular}{lcccccccccc}
\hline ID & $\begin{array}{c}\text { F1 } \\
\text { pre-op }\end{array}$ & $\begin{array}{c}\text { F1 post-VTA } \\
\text { DBS }\end{array}$ & $\begin{array}{c}\text { F2 } \\
\text { pre-op }\end{array}$ & $\begin{array}{c}\text { F2 post-VTA } \\
\text { DBS }\end{array}$ & $\begin{array}{c}\text { F3 } \\
\text { pre-op }\end{array}$ & $\begin{array}{c}\text { F3 post-VTA } \\
\text { DBS }\end{array}$ & $\begin{array}{c}\text { F4 } \\
\text { pre-op }\end{array}$ & $\begin{array}{c}\text { F4 post-VTA } \\
\text { DBS }\end{array}$ & $\begin{array}{c}\text { CH-QoL TOT } \\
\text { pre-op }\end{array}$ & $\begin{array}{c}\text { CH-QoL TOT } \\
\text { post-VTA DBS }\end{array}$ \\
\hline 1 & 22 & 10 & 8 & 7 & 5 & 5 & 12 & 12 & 47 & 34 \\
2 & 27 & 12 & 22 & 14 & 6 & 1 & 16 & 10 & 71 & 37 \\
3 & 27 & 24 & 20 & 13 & 4 & 4 & 15 & 16 & 66 & 57 \\
4 & 36 & 36 & 31 & 22 & 8 & 8 & 18 & 17 & 93 & 83 \\
5 & 35 & 33 & 30 & 32 & 7 & 7 & 14 & 16 & 86 & 88 \\
6 & 35 & 26 & 30 & 36 & 4 & 6 & 18 & 15 & 87 & 83 \\
7 & 31 & 29 & 36 & 32 & 7 & 8 & 18 & 16 & 92 & 85 \\
8 & 30 & 33 & 37 & 33 & 7 & 7 & 14 & 16 & 88 & 89 \\
9 & 27 & 30 & 19 & 29 & 6 & 8 & 17 & 20 & 69 & 87 \\
10 & 24 & 16 & 32 & 26 & 8 & 8 & 13 & 10 & 77 & 60 \\
M & 29.4 & 24.9 & 26.5 & 24.4 & 6.2 & 6.2 & 15.5 & 14.8 & 77.6 & 70.3 \\
(SD) & $(4.8)$ & $(9.2)$ & $(9.1)$ & $(9.9)$ & $(1.5)$ & $(2.3)$ & $(2.2)$ & $(3.2)$ & $(14.5)$ & $(21.6)$ \\
\hline
\end{tabular}

F1 restriction of activities of daily living, F2 impact on mood and interpersonal relationship, F3 pain and anxiety, F4 lack of vitality, $M$ mean, SD standard deviation, TOT total score, VTA-DBS ventral tegmental area deep brain stimulation 
represents a total score indicating global anxiety (HADS-A) or depression (HADS-D). On both Depression and Anxiety subscales scores range from 0 to 21, with higher scores indicating more severe depression or anxiety.

\section{Pain}

The Headache Impact Test (HIT-6) [14] is a six-item questionnaire used to measure the adverse impact of headaches on role and social functioning, cognitive functioning, vitality,psychological distress, and pain severity. The scores range from 36 to 78, and functional impact due to headaches can then be categorized into four groups: little or no impact $(<49)$, some impact $(50-55)$, substantial impact (56-59), and severe impact (60-78).

The McGill Pain Questionnaire (MPQ) [15] is a measure of subjective pain experience that includes 78 adjectives describing the quality of pain, divided across four domains, namely sensory, affective, evaluative, and miscellaneous aspects of pain. The total possible score ranges from 0 to 78 , with higher scores indicating worse pain.

The Pain Behaviour Checklist (PBC) [16] is a selfreport assessment to quantify three classes of pain behaviours: help seeking, avoidance, and complaint.

\section{Data analysis}

All data were analyzed using the computing environment $\mathrm{R}$ [17]. Means and standard deviations were calculated for all variables. Paired samples t-tests were used to examine whether a significant change in $\mathrm{CH}-\mathrm{QoL}$, SF-36 domains, mood and/or pain had occurred from before to after VTA-DBS. Pearson correlational analyses were performed to explore the relationship between the change scores in the $\mathrm{CH}-\mathrm{QoL}$ scale (before and after VTA-DBS) and change scores in measures of the SF-36, mood, and pain. We calculated and reported $95 \%$ confidence intervals for all analyses.

Cohen's d effect size was calculated for the CH-QoL total score and its 4 subdomains:

$$
\text { Cohen'sd }=\frac{\text { mean }(\text { post })-\text { mean }(\text { baseline })}{\text { StandardDeviation }}
$$

A d value of 0.2-0.4 reflects a small effect, 0.5-0.7 an intermediate effect, and $0.8-1$ a large effect.

Standardized response mean (SRM) was calculated for the $\mathrm{CH}-\mathrm{QoL}$ total score and the foursubdomains:

$$
S R M=\frac{\text { mean }(\text { post })-\text { mean }(\text { baseline })}{\text { StandardDeviation }(\Delta)}
$$

Cohen's d and SRM are standardized indices of power to detect a true change, and larger values indicate higher sensitivity to change $[7,18]$.

\section{Results}

There was some individual variability in the effects of VTA-DBS on HAL (see Tables 1 and 3). While the majority of 7 patients showed significant and clinically notable improvement of their HAL after VTA-DBS compared to before surgery, this was not the case for patients 4,5 and 9 .

\section{CH-QoL scale sensitivity to change with VTA-DBS}

Participants were evaluated within one month prior to the DBS procedure and one year or more postoperatively (mean 12 months $\mathrm{SD}=1.8$ ). $\mathrm{CH}-\mathrm{QoL}$ total score and the four sub-domains scores for pre and post VTA are presented in Table 3; Fig. 1. The CH-QoL total score was significantly reduced after $(\mathrm{M}=70.3, \mathrm{SD}=$ 21.6) compared to before VTA-DBS $(\mathrm{M}=77.6, \mathrm{SD}=$ 14.5), $\mathrm{t}(9)-2.0, p=0.03, d=-0.6)$, indicating better health-related quality of life reported by the patients after VTA-DBS. The CH-QoL 'restriction of daily activities' score was also significantly reduced after $(M=$ 24.90, $\mathrm{SD}=9.29)$ compared to before VTA-DBS $(\mathrm{M}=$ 29.40, $\mathrm{SD}=4.8), \mathrm{t}(9)-2.28, p=0.001, d=-0.7)$, indicating better daily functioning after surgery. The scores on the other two subscales 'mood and interpersonal relationships' and 'lack of vitality' subscales were lower after (respectively $\mathrm{M}=24.40, \quad \mathrm{SD}=9.9 ; \quad \mathrm{M}=14.80, \quad \mathrm{SD}=3.19)$ compared to before VTA-DBS (respectively $\mathrm{M}=26.50$, $\mathrm{SD}=9.1 ; \mathrm{M}=15.50, \mathrm{SD}=2.2$ ), indicating better healthrelated functioning of patients after VTA-DBS. However, the change on these subscales was not significant (see Tables 3 and Fig. 1). For the CH-QoL total score and the $\mathrm{CH}-\mathrm{QoL}$ restriction ADL Cohen's d were respectively 0.6 and for 0.7 , indicating intermediate effects. These results suggest that the CH-QoL scale is sensitive to change and particularly the total score and the activities of daily living subscore are significantly improved following improvement of headaches after VTA-DBS surgery.

\section{Correlation of CH-QoL scale total change score (before and after VTA-DBS) with change scores of the other measures}

Pearson correlational analyses were performed to explore the relationship between the change score in $\mathrm{CH}$ QoL scale (before and after VTA-DBS) and the change scores in the clinical outcome composite score of headache frequency and severity (HAL) and the other measures of mood, pain and pain behaviour, and quality of life (see Fig. 2).

\section{Headache load}

There was a significant negative correlation between $\mathrm{CH}-\mathrm{Q}$ oL total score and HAL $r=-0.60, p=0.03$, 
Table $3 \mathrm{CH}-\mathrm{Q}$ L sensitivity to change for the patients with cluster headache who underwent ventral tegmental area deep brain stimulation (VTA-DBS).

\begin{tabular}{|c|c|c|c|c|c|c|c|}
\hline CH-QoL subscale & Baseline (SD) & Post (SD) & Mean Diff & Paired t-test $(95 \% \mathrm{Cl})$ & $p$-values & Cohen's d & SRM \\
\hline ADL Restriction & $29.4(4.8)$ & $24.9(9.2)$ & -4.5 & $-2.28(-6.8,-0.2)$ & $0.01^{*}$ & -0.7 & -0.7 \\
\hline Mood \& interpersonal relations & $26.5(9.1)$ & $24.4(9.9)$ & -2.1 & $-1.52(-5.4,0.9)$ & 0.14 & -0.3 & -0.4 \\
\hline Pain and anxiety & $6.2(1.5)$ & $6.2(2.3)$ & 0.0 & $-1.02(-1.4,0.47)$ & 0.30 & -0.3 & -0.3 \\
\hline Lack of vitality & $15.5(2.2)$ & $14.8(3.2)$ & -0.7 & $-1.08(-2.6,0.9)$ & 0.29 & -0.3 & -0.2 \\
\hline $\mathrm{CH}$-QoL total score & $77.6(14.5)$ & $70.3(21.6)$ & -7.3 & $-2.05(-14.4,0.3)$ & $0.03^{*}$ & -0.6 & -0.5 \\
\hline \multicolumn{8}{|l|}{ Clinical Outcome } \\
\hline $\mathrm{HAL}^{+}$ & $987.1(649.5)$ & $553.45(761.7)$ & -443.7 & $-2.60(-858.5,-102)$ & $0.01 *$ & -0.6 & -0 \\
\hline
\end{tabular}

$\mathrm{ADL}$ activities of daily living, $\mathrm{CH}-\mathrm{Q}$ oL cluster headache quality of life scale, $\mathrm{Cl}$ confidence interval, HAL headache load (composite of frequency, severity and duration of cluster headache episodes), Mean DIFF = Mean Post - Mean Baseline, SD standard deviation, SRM standard mean response, ${ }^{*}$ significant $p$-values ${ }^{+}$ cluster headache patients

indicating that lower scores on the $\mathrm{CH}-\mathrm{QoL}$ (better QoL) are associated with the reduction of frequency, duration and severity of headache attacks suggesting the sensitivity to change of $\mathrm{CH}-\mathrm{QoL}$.

\section{Generic quality of life}

We found a significant negative correlation between the $\mathrm{CH}-\mathrm{QoL}$ total score and the SF-36 role physical $r=-0.87$, $p<0.05$. This indicates that lower scores on the $\mathrm{CH}-\mathrm{QoL}$ (better QoL) are associated with improvement of aspects of quality of life assessed by the generic SF-36 after VTA-DBS.

\section{Mood}

We found significant positive correlations between the $\mathrm{CH}$-QoL total score and ratings of $\operatorname{mood}$ on the BDI $r=$ $0.63, p<0.05$, indicating that lower $\mathrm{CH}-\mathrm{QoL}$ score

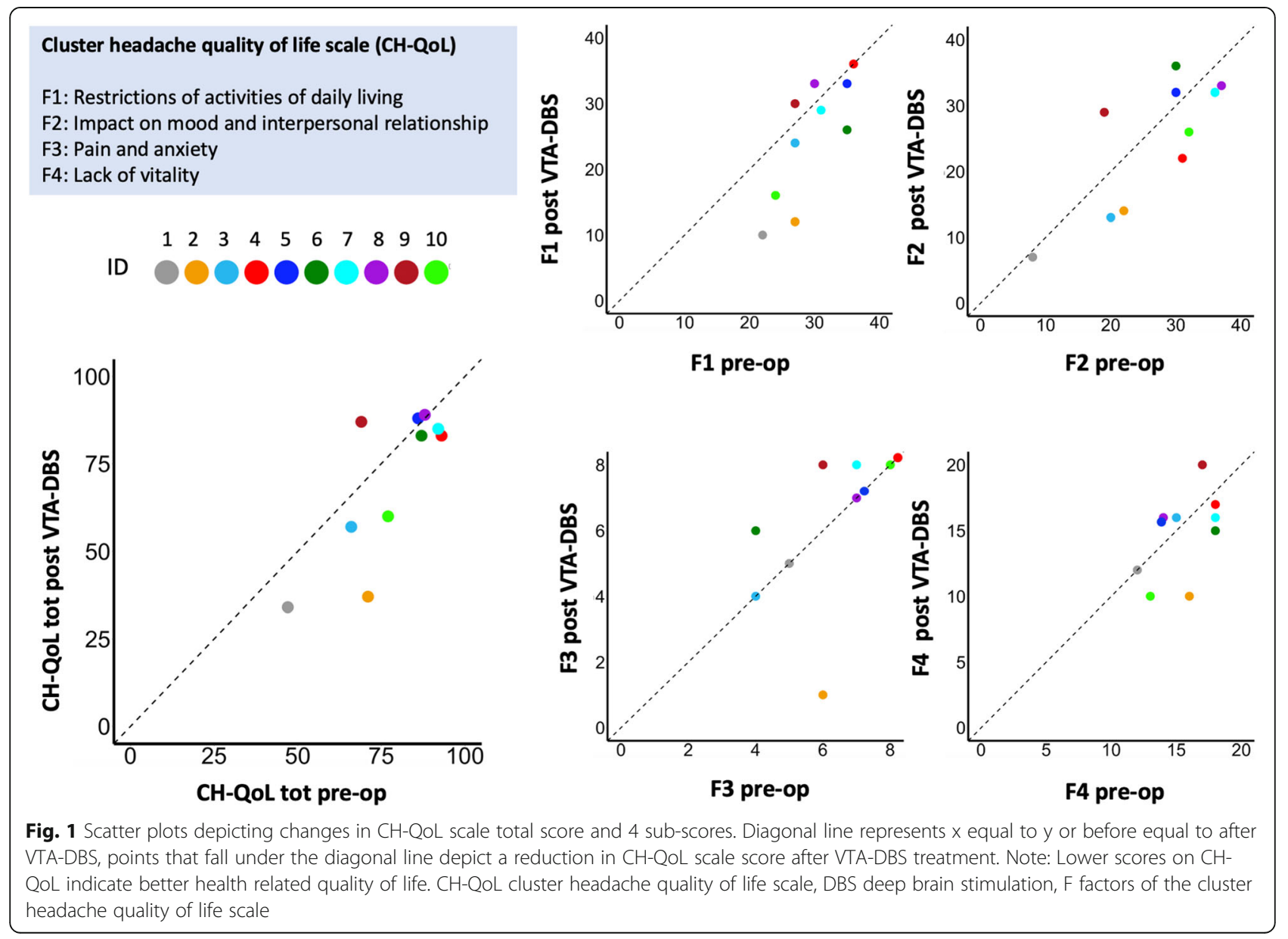



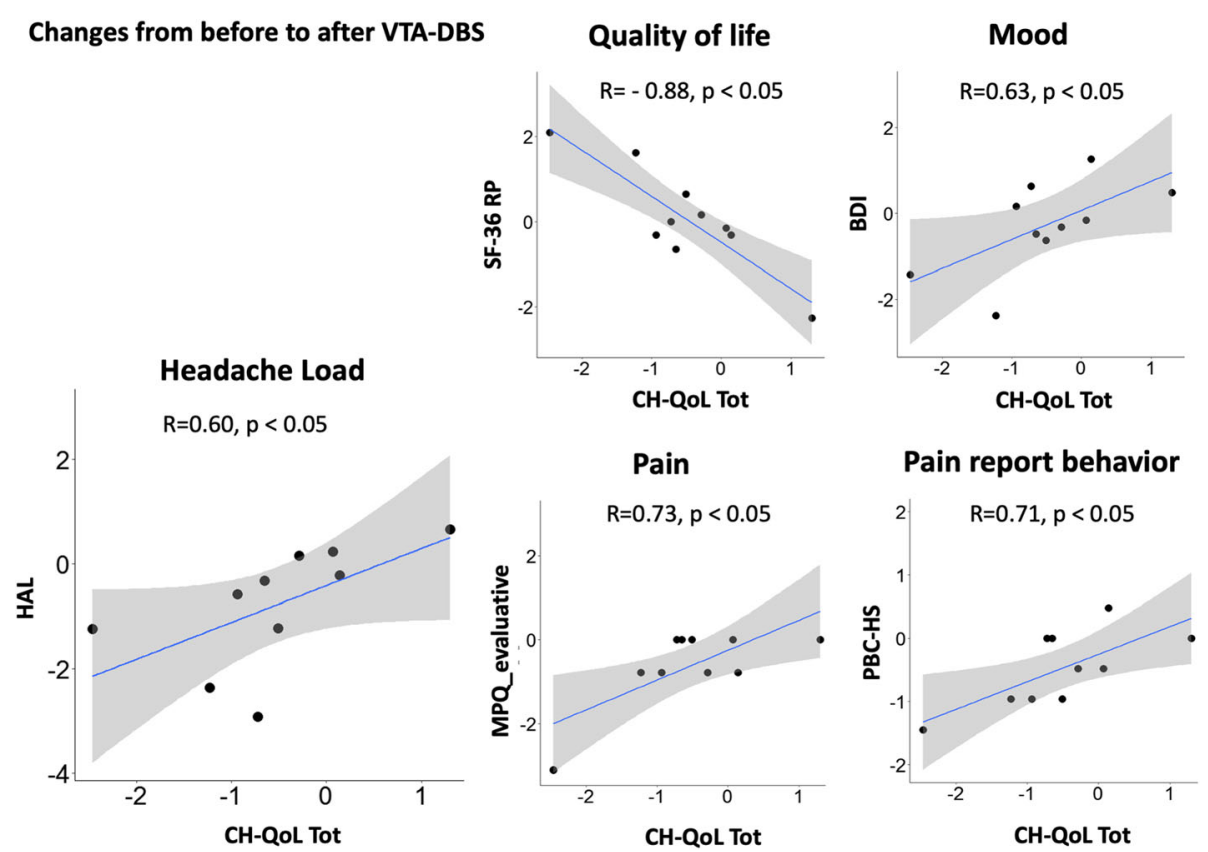

Fig. 2 Scatter plots representing significant Pearson correlations between changes in $\mathrm{CH}-\mathrm{Q}$ L total score and changes in other measures of quality of life (SF-36), mood (BDI-II) and pain (McGill Pain Questionnaire evaluative scale, HIT-6) and Pain Behaviour Checklist help-seeking behaviours (PBC-HS) from before to after VTA-DBS. Note: CH-QoL total higher scores indicate poorer health related quality of life. SF-36 higher scores indicate better health related quality of life, BDI-II, HIT-6, McGill Pain Questionnaire (MPQ) lower scores indicate better functioning. BDI-II Beck depression inventory-II, HAL headache load, HIT-6 headache impact test-6, RP role physical, Tot CH-QoL total score

(better QoL) is associated with a reduction of depressive symptoms after VTA-DBS.

\section{Pain}

There were significant positive correlations between the $\mathrm{CH}-\mathrm{Q}$ oL total score and the evaluative domain on the McGill Pain Questionnaire $r=0.73, p<0.05$, and a correlation approaching significance with HIT6 $r=0.58$, $p=0.06$, indicating that lower/improved CH-QoL scores are associated with a reduction of pain evaluation and the impact of pain after VTA-DBS.

\section{Pain behaviour}

We found significant positive correlations between the $\mathrm{CH}-\mathrm{QoL}$ total score and the help-seeking domain on the Pain Behaviour Checklist (PBC) $r=0.71, p<0.05$, suggesting that lower/improved $\mathrm{CH}-\mathrm{QoL}$ score is associated with reduction of pain related help-seeking behaviours after VTA-DBS.

\section{Discussion}

Since there was no disease-specific measure of QoL for the most common TAC, cluster headache, we recently developed and validated the 28 item CH-QoL and demonstrated that it had good construct and convergent validity, internal consistency and test-retest reliability [6]. The aim of the present study was to evaluate the sensitivity of the CH-QoL scale to change by administering it to 10 patients with cluster headache before and one year or longer after VTA-DBS to determine whether it reflected the improvement in headache load observed following surgery. The results showed that the $\mathrm{CH}-\mathrm{QoL}$ total score and the four subscales all reflected improved quality of life following VTA-DBS compared to before surgery, a change that was significant for the total score and the main subscale of 'restrictions of ADL'. The sensitivity of the CH-QoL to change was further confirmed by two other aspects of the results. First, the change scores of the CH-QoL total score and the reduction of headache load were significantly related, indicating that the reduction of the frequency, duration and severity of headache attacks after VTA-DBS are reflected by the pre versus post-operative change scores of the $\mathrm{CH}-\mathrm{QoL}$. Second, the associations of change scores of the $\mathrm{CH}$ QoL total score with change scores of the generic QoL measure the SF-36, indices of mood (BDI), pain (HIT-6 and McGill), and pain-related behaviors (Pain Behaviour Checklist-Help Seeking behaviours) were in the expected direction; all reflecting an association between the improvement of disease-specific and generic QoL, mood, pain and pain-related behaviours following VTA-DBS surgery.

HADS-A showed no significant association with the $\mathrm{CH}-\mathrm{Q} o \mathrm{~L}$ total score or with the "Pain and Anxiety" 
subscale. This might be because the $\mathrm{CH}$-QoL subscale measures specific anxiety relating to having an attack rather than generalized anxiety symptoms as in the HADS-A. Also, having a newly implanted DBS device might have contributed to anxiety in many ways, such as fear of loss of effect, worries about maintenance and charging, concerns about infection in the period following surgery. While change on the 'restrictions of ADL' subscale was significant and the other three subscales of the $\mathrm{CH}-\mathrm{QoL}$ also reflected improved functioning following VTA-DBS, these other features of $\mathrm{CH}-\mathrm{QoL}$ such as 'mood and interpersonal relations' and 'lack of vitality' 'pain and anxiety' may require a longer time post-DBS to adequately and significantly reflect change following reduction of headache load, since interpersonal relations and vitality unlike daily activities may be aspects of quality of life that require a longer period for a move towards readjustment and 'normalization'. This is a hypothesis thatcan be tested by further follow-up of this sample or other surgical or medically treated samples for a longer period of say 3 or 4 years after VTA-DBS.

As for most patients with cluster headache, standard medical treatment would entail medication, future studies could also further evaluate the sensitivity to change of $\mathrm{CH}-\mathrm{QoL}$ by examining its responsiveness to change following effective medical treatment.

\section{Conclusions}

In conclusion, the lack of a gold standard to assess QoL in $\mathrm{CH}$ is currently limited to using a combination of generic tests not explicitly devised to assess $\mathrm{CH}$ patients. Our study indicates that $\mathrm{CH}-\mathrm{QoL}$ responds similarly to other validated generic scales, supporting $\mathrm{CH}$-QoL's validity and sensitivity to detect $\mathrm{CH}$ patients' clinical changes following surgical treatment. Thus, these findings support the utility of $\mathrm{CH}-\mathrm{QoL}$ for clinicians to assess responsiveness following other medical therapies. However, the small number of patients and the lack of testing for other medical therapies limit the generalizability of our results on CH-QoL's sensitivity to change. Ultimately, confirmatory studies in a large population should determine whether $\mathrm{CH}-\mathrm{QoL}$ could substitute the generic quality of life scales currently used in clinical practice.

\footnotetext{
Abbreviations

ADL: activities of daily living; BDI-II: Beck depression inventory-II; $\mathrm{CH}$ : cluster headache; $\mathrm{CH}-\mathrm{QoL}$ : cluster headache quality of life scale; HADS: Hospital anxiety and depression rating scale; HAL: headache load; HIT6: headache impact test-6; QoL: quality of life; TACs: trigeminal autonomic cephalalgias; VTA-DBS: ventral tegmental area deep brain stimulation
}

\section{Acknowledgements}

We wish to thank all the patients, family members and staff from all the units that participated in the study.

\section{Authors' contributions}

D.C. was involved in the study's conceptualization, execution, data analysis and interpretation, writing of the first draft and review and critique of the manuscript. A.R. was involved in data collection. H.A. review and critique of the manuscript, S.L. review and critique of the manuscript, S.C. review and critique of the manuscript, J.H. review and critique of the manuscript, L.Z. review and critique of the manuscript, M.M. review and critique of the manuscript, M.J. was involved in conceptualization of the study, data analysis and interpretation, drafting and review of the manuscript. The author(s) read and approved the final manuscript.

\section{Funding}

The authors received no financial support for the research, authorship, and/ or publication of this article.

\section{Declarations}

\section{Ethics approval and consent to participate}

This study was approved by the Queen Square National Hospital for Neurology and Neurosurgery local ethics committee. All participants gave written informed consent.

\section{Consent for publication}

Not applicable.

\section{Competing interests}

$D C, A R, H A, J H$, and $M J$ have no disclosures. SL has received payment for attending advisory meetings and development of presentation from Allergan Novartis, Eli Lilly and TEVA. SC has received an educational grant from Abbott. MSM serves on the advisory board for Abbott, Allergan, Eli Lilly, Medtronic, Novartis, TEVA; has received payment for the development of educational presentations from Allergan, electroCore, Eli Lilly, Medtronic, Novartis, and TEVA; and has received research grants from Abbott, electroCore and Medtronic. LZ has received honoraria for participating in educational activities from Medtronic and Boston Scientific.

\section{Author details}

${ }^{1}$ Unit of Functional Neurosurgery, Department of Clinical and Movement Neurosciences, University College London (UCL) Institute of Neurology, National Hospital for Neurology and Neurosurgery, 33 Queen Square, WC1N 3BG London, UK. ${ }^{2}$ Hinda and Arthur Marcus Institute for Aging Research, Hebrew SeniorLife, Harvard Medical School, Boston, MA, USA. ${ }^{3}$ Deanna and Sidney Wolk Center for Memory Health, Hebrew SeniorLife, Boston, MA, USA. ${ }^{4}$ Department of Psychology, Queen Mary University of London, London, UK. ${ }^{5}$ Headache and Facial Pain Group, UCL Queen Square Institute of Neurology, The National Hospital for Neurology and Neurosurgery, London, UK. ${ }^{6} \mathrm{MOE}$ Key Lab for Neuroinformation, The Clinical Hospital of Chengdu Brain Science Institute, University of Electronic Science and Technology of China, Chengdu, China.

Received: 15 January 2021 Accepted: 3 May 2021

Published online: 06 June 2021

\section{References}

1. Lambru G, Matharu MS (2012) Trigeminal autonomic cephalalgias: A review of recent diagnostic, therapeutic and pathophysiological developments. Ann Indian Acad Neurol 15:S51-S61. https://doi.org/10.4103/0972-2327.1 00007

2. Torkamani M, Ernst $L$, Cheung LS, Lambru G, Matharu M, Jahanshahi M (2015) The Neuropsychology of Cluster Headache: Cognition, Mood, Disability, and Quality of Life of Patients With Chronic and Episodic Cluster Headache. Headache. 55(2):287-300. doi: https://doi.org/10.1111/head.12486

3. Abu Bakar N, Tanprawate S, Lambru G, Torkamani M, Jahanshahi M, Matharu M (2016) Quality of life in primary headache disorders: A review. Cephalalgia Int J Headache 36(1):67-91. https://doi.org/10.1177/0333102415580099

4. D’Amico D, Raggi A, Grazzi L, Lambru G (2020) Disability, Quality of Life, and Socioeconomic Burden of Cluster Headache: A Critical Review of Current Evidence and Future Perspectives. Headache J Head Face Pain 60(4):809818. doi:https://doi.org/10.1111/head.13784

5. Ertsey C, Manhalter N, Bozsik G, Afra J, Jelencsik I (2004) Health-related and condition-specific quality of life in episodic cluster headache. Cephalalgia 
Int J Headache 24(3):188-196. https://doi.org/10.1111/j.1468-2982.2003. 00655.x

6. Abu Bakar N, Torkamani M, Tanprawate S, Lambru G, Matharu M, Jahanshahi M (2016) The development and validation of the Cluster Headache Quality of life scale (CHQ). J Headache Pain. 17;1. doi:https://doi.org/10.1186/s10194016-0674-1

7. Liang MH (2000) Longitudinal construct validity: establishment of clinical meaning in patient evaluative instruments. Med. Care. 38(9 Suppl):I84-90.

8. Akram H et al (2016) Ventral tegmental area deep brain stimulation for refractory chronic cluster headache. Neurol. 86:1676-1682. https://doi.org/1 0.1212 WNL.00000000000002632.

9. Cappon D et al (2019) Ventral tegmental area deep brain stimulation for chronic cluster headache: Effects on cognition, mood, pain report behaviour and quality of life. Cephalalgia. 39(9):1099-1110. doi: https://doi.org/10.1177/ 0333102419839957

10. Nowacki A, Schober M, Nader L, Saryyeva A, Nguyen TAK, Green AL, and Aziz TZ. (2020). Deep Brain Stimulation for Chronic Cluster Headache: MetaAnalysis of Individual Patient Data. Annals of neurology. 88(5):956-969.

11. Jenkinson C, Coulter A, Wright L (1993) Short form 36 (SF36) health survey questionnaire: normative data for adults of working age. BMJ 306(6890): $1437-1440$

12. Beck AT, Steer RA, Brown G (1996) Beck depression inventory-II. Psychol. Assess.https://doi.org/10.1037/t00742-000.

13. Zigmond AS, Snaith RP (1983) The hospital anxiety and depression scale. Acta Psychiatr Scand 67(6):361-370. https://doi.org/10.1111/j.1600-0447.1 983.tb09716.x

14. Kosinski M et al (2003) A six-item short-form survey for measuring headache impact: The HIT- TMM $^{\text {. }}$ Qual Life Res 12(8):963-974

15. Melzack R (1975) The McGill Pain Questionnaire: major properties and scoring methods. Pain. 1(3):277-299.

16. Philips HC (1987) Avoidance behaviour and its role in sustaining chronic pain. Behav Res Ther 5(4):273-279. doi:https://doi.org/10.1016/00057967(87)90005-2

17. R Core Team (2017) R: A language and environment for statistical computing. R Foundation for Statistical Computing, Vienna. URL https:// www.R-project.org/.

18. Cohen J (2013) Statistical power analysis for the behavioral sciences Academic press

\section{Publisher's Note}

Springer Nature remains neutral with regard to jurisdictional claims in published maps and institutional affiliations.

Ready to submit your research? Choose BMC and benefit from:

- fast, convenient online submission

- thorough peer review by experienced researchers in your field

- rapid publication on acceptance

- support for research data, including large and complex data types

- gold Open Access which fosters wider collaboration and increased citations

- maximum visibility for your research: over $100 \mathrm{M}$ website views per year

At BMC, research is always in progress.

Learn more biomedcentral.com/submissions 